\title{
SHEAR RESISTANCE AND ITS INFLUENCES IN EUROCODES EN 1993-1-1 AND EN 1999-1-1
}

\author{
I. Baláž ${ }^{*}$, Y. Koleková ${ }^{* *}$, L. Moroczová ${ }^{* * *}$
}

\begin{abstract}
Critical analysis of definitions of shear areas of I- and H-sections. Results of the large parametrical study. Improvement proposals for the new generation of Eurocodes EN 1993-1-1 and EN 1999-1-1.
\end{abstract}

Keywords: shear area, elastic shear resistance, plastic shear resistance, Eutocodes

\section{Introduction}

The paper describes scientific backgrounds of some topics investigated for the purpose of the new generation of Eurocodes which will be available for technical public in the year 2021. The first author is a member of 5 working groups of the technical committee CEN/TC 250 Structural Eurocodes: a) WG EN 1993-1-1 Design of steel structures, Part 1-1 General rules and rules for buildings, b) WG EN 1993-1-3 Design of steel structures, Part 1-3 General rules - Supplementary rules for cold-formed members and sheeting guidelines, c) WG EN 1993-1-5 Design of steel structures, Part 1-5 Plated structural elements, d) WG EN 1993-2 Design of steel structures, Part 2 Steel bridges, e) WG EN 1999-1-1 Design of aluminium structures, Part 1-1 General structural rules.

The third final drafts of prEN 1993-1-1 and prEN 1999-1-1 are available in these days. They may be commented by using CIB ballot, writing any comments into the CEN comments template and submitted to CEN/TC 250 Structural Eurocodes through the National Standardization Body.

The paper analyzes the relevant clauses of these two drafts and proposes their improvements.

\section{Shear area and torsion constant}

According to (EN 1993-1-1, 2005) the shear area for I and H sections may be taken as follows: a) Rolled I and $\mathrm{H}$ sections, load parallel to web:

$$
A_{V z, E C 3, r}=\max \left(A_{V z . E N} ; \eta h_{w} t_{w}\right)
$$

where $A_{V z, E N}$ may be written in two different forms:

$$
\begin{gathered}
A_{V z, E N}=A-2 b t_{f}+\left(t_{w}+2 r\right) t_{f} \\
A_{V z, E N}=h_{w} t_{w}+(4-\pi) r^{2}+\left(t_{w}+2 r\right) t_{f}
\end{gathered}
$$

factor $1.0 \leq \eta \leq 1.2$ depends on decision of National Annexes of different countries,

Prof. Ing. Ivan Baláž, PhD.: Department of Metal and Timber Structures, Faculty of Civil Engineering, Slovak University of Technology in Bratislava, Slovak Republic, Radlinského 11; 810 05, Bratislava; SK, ivan.balaz@stuba.sk

** $\quad$ Assoc. Prof. Ing. Yvona Koleková, PhD.: Department of Structural Mechanics, Faculty of Civil Engineering, Slovak University of Technology in Bratislava, Slovak Republic, Radlinského 11; 810 05, Bratislava; SK, yvona.kolekova@stuba.sk

*** Ing. Lýdia Moroczová, external PhD student at Department of Metal and Timber Structures, Faculty of Civil Engineering, Slovak University of Technology in Bratislava, Slovak Republic, Radlinského 11; 810 05, Bratislava, lidka.mo@gmail.com 
$A$ is the cross-sectional area, $b, t_{f}$ are the width and thickness of the flange, $h_{w}, t_{w}$ are the width and thickness of the web, $r$ is the radius of root fillet, $h_{f}=h_{w}+t_{f}$ or $h_{f}=h-t_{f}$, where $h$ is the overall depth of the I and $\mathrm{H}$ section.

The value $\eta=1.2=6 / 5$ for steel grades S235 to S460 has origin in the experiments. In the tests on beams with stocky webs the ultimate resistance in shear reaches 0.7 to 0.8 times the yield strength in tension, which corresponds approximately to the increase of $20 \%$ of the shear yield strength. One reason for this is strain hardening of steel, which may be utilized because it does not give excessive deformations. The other reason is probably a contribution from the flanges. These two effects cannot be easily separated and have not been studies in detail. There are no tests results available supporting this increase for higher steel grades than S460, which have relatively lower strain hardening. That is why $\eta=1.0$ for steel grades over S460. There are test results available on rolled I sections showing no interaction at all for combined shear and bending. This is even true if the increased plastic shear resistance using $\eta=1.2$ is used, which can be resisted at the same time as the full plastic bending moment (Beg et al, 2010).

The relevant scientific background of the formulae (2) and (3) is not known to the authors. The relative shear area $A_{V z, E N} /\left(h_{w} t_{w}\right)$ may achieve the value up to 1.9 , which for the rolled I and $\mathrm{H}$ sections was not confirmed by the experiments.

b) Rolled I and H sections, load parallel to flanges:

$$
A_{V y, E C 3, r}=2 b t_{f}
$$

This may be find only in the draft (prEN 1993-1-1, 2017). In the current (EN 1993-1-1, 2005) this information is missing.

c) Welded I and H sections, load parallel to web

$$
A_{V z, E C 3, w}=\eta h_{w} t_{w}
$$

d) Welded I and H sections, load parallel to flanges:

$$
A_{V y, E C 3, w}=A-h_{w} t_{w}=2 b t_{f}
$$

Instead of expressions (4) and (6) one would expect the value $A_{V y}=2 b t_{f} 5 / 6$ valid for two rectangles.

According to (EN 1999-1-1, 2007) the shear area may be taken as follows:

e) Unwelded I sections without holes, load parallel to web

$$
A_{V z, E C 9}=h_{w} t_{w}
$$

f) Solid bar without welds and holes

$$
A_{V z, E C 9}=0.8 h_{w} t_{w}
$$

The shear areas $A_{V z}, A_{V y}$ may be calculated with the help of area shear factors $v_{z}<1.0$ and $v_{y}<1.0$, respectively. In similar way may be defined shear torsion constant $I_{t, s}$ (not used in Eurocodes) with the help of torsion constant shear factor $v_{\omega}>1.0$ (this one is greater than one):

$$
A_{\mathrm{Vz}}=v_{\mathrm{z}} A=\frac{I_{\mathrm{y}}^{2}}{\int_{\mathrm{A}}\left[\frac{S_{\mathrm{y}}(s)}{t(s)}\right]^{2} d A}, \quad A_{\mathrm{Vy}}=v_{\mathrm{y}} A=\frac{I_{\mathrm{z}}^{2}}{\int_{A}\left[\frac{S_{\mathrm{z}}(s)}{t(s)}\right]^{2} d A}, I_{\mathrm{t}, \mathrm{s}}=v_{\omega} I_{\mathrm{t}}=\frac{I_{\omega}^{2}}{\int_{A}\left[\frac{S_{\omega}(s)}{t(s)}\right]^{2} d A}
$$

where the dimensionless shear factors are defined as follows

$$
v_{\mathrm{z}}=\frac{I_{\mathrm{y}}^{2}}{A \int_{A}\left[\frac{S_{\mathrm{y}}(s)}{t(s)}\right]^{2} d A}, \quad v_{\mathrm{y}}=\frac{I_{\mathrm{z}}^{2}}{A \int_{A}\left[\frac{S_{\mathrm{z}}(s)}{t(s)}\right]^{2} d A}, \quad v_{\omega}=\frac{I_{\omega}^{2}}{I_{t, s} \int_{A}\left[\frac{S_{\omega}(s)}{t(s)}\right]^{2} d A}
$$


The name area shear factor is used in (Marti, 2013). There are two kinds of the inverse quantities to the area shear factors $v_{z}<1.0, v_{y}<1.0$. The first ones are called the shear shape coefficients $\alpha_{z}=v_{z}^{-1}>1.0$, $\alpha_{y}=v_{y}^{-1}>1.0$ (Timoshenko, Gere, 1972). The value of the shear shape coefficient for the rectangular cross-section is $6 / 5=1.2$ and for the circle is $10 / 9$. The second ones are called shear coefficients (Timoshenko, Gere, 1972). The value of the shear coefficient for the rectangular cross-section is $3 / 2=$ 1.5 and for the circle is $4 / 3$. In these cases the shear coefficients are numerical factors which with the average shear stress must be multiplied in order to obtain the maximum shear stress at the centroid of the cross-section (Timoshenko, 1940). The approximate value of the shear shape coefficient and also of the shear coefficient of the regular I-sections is given by the ratio $\alpha_{z}=A /\left(h_{w} t_{w}\right)$ what means that $A_{V z}=h_{w} t_{w}$. The shear coefficients for different cross-section shapes were investigated by many scientists (Timoshenko, 1940; Timoshenko, Goodier, 1970; Timoshenko, Gere, 1972; Cowper, 1966; Gruttmann, Wagner, 2001).

\section{Comparisons of different shear area formulae valid for I section}

The above formulae enabled to perform the large parametrical study showing comparisons of shear area values calculated from the different formulae valid for IPE, HEA, HEB and HEM sections of all their sizes. The part of the results of the parametrical study are given in Figures 1 (HEM 100) and 2 (IPE 100).

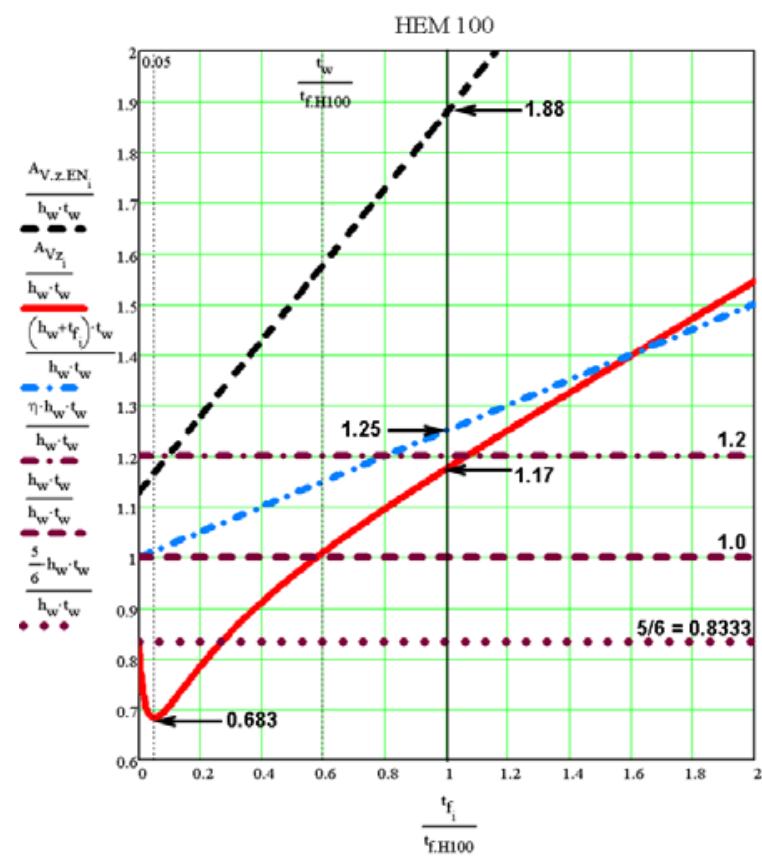

Fig. 1: Comparison of relative shear areas for HEM 100. The reference value is $h_{w} t_{w}$.

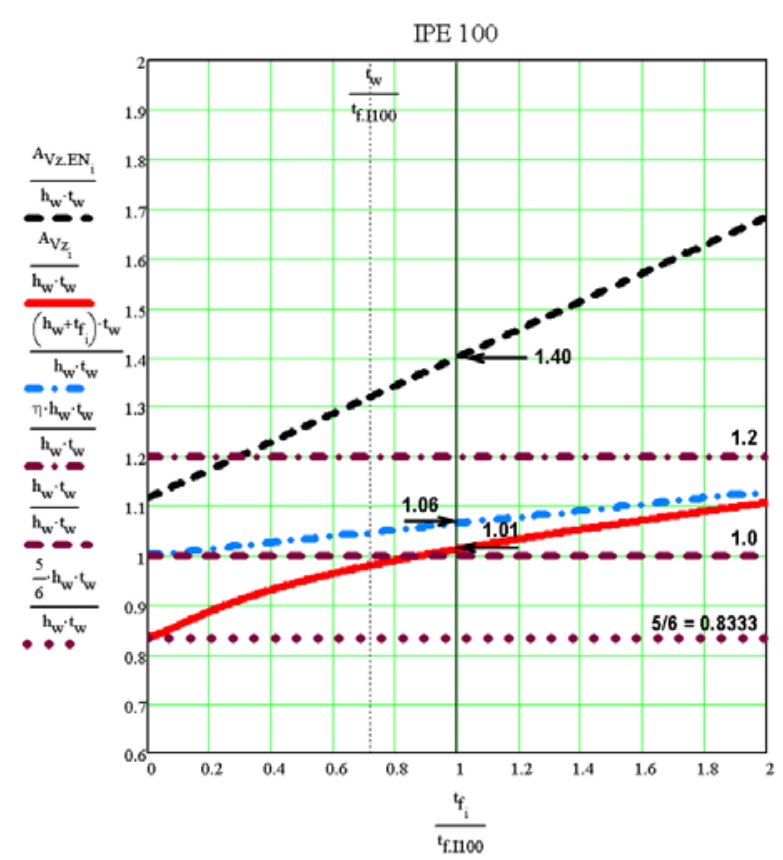

Fig. 2: Comparison of relative shear areas for IPE 100. The reference value is $h_{w} t_{w}$.

The results in the figures are given in dimensionless form to achieve general validity. On the horizontal axis there are the relative flange thicknesses. They are the ratios of continuously changing flange thickness to the flange thickness of the section under investigation $t_{f . H 100}$ or $t_{f . H 100}$. The vertical line going through the value 1.0 relates to the relative flange thickness of the section under investigation. The range of the relative flange thicknesses on the horizontal axis is from 0 (rectangular section $h_{w} t_{w}$ ) till 2 (the flange thickness is 2-times greater than the flange thickness of the section under investigation). On the vertical axis there are the different relative shear areas. It means that the different shear areas are divided by the reference value $h_{w} t_{w}$, which is kept constant in the parametrical study. The values of flange width $b$ and the radius of root fillet $r$ are kept constant in this study too. The dotted horizontal straight line marks the relative shear area $5 / 6$ valid for the rectangular section. The dashed horizontal straight line denotes the relative shear area 1 , when the shear area is $h_{w} t_{w}$ and $\eta=1.0$. The horizontal dot and dash straight line is valid for the maximum possible recommended value of the relative shear area $\eta=1.2=6 / 5$, when the shear area is $1.2 h_{w} t_{w}$. The bottom solid line is valid for shear area $A_{V z}$ calculated 
according to formula (9a). The sloping dot and dash straight line is valid for shear area $h_{f} t_{w}=\left(h_{w}+t_{w}\right) t_{w}$ used in the clause 7.5.3 (756) of German standard (DIN 18800-1, 2008). The sloping dashed straight line is valid for $A_{V z, E N}$ defined by formulae (2) or (3) which according to (1) should be not lesser than $\eta h_{w} t_{w}$.

One would expect the minimum value of the relative shear area 5/6 $=0.8333$ valid for the rectangle (I section without flanges). Nevertheless, for the HEM 100 section (Figure 1) with the very small (not real) ratios $t_{f} / t_{f . H 100}=0.05$ and $2 b t_{f} /\left(h_{w} t_{w}\right)=0.22$ the relative shear area is 0.683 . The minimum values for such not real sections are indicated by the first vertical line. The other vertical line denoted by symbol $t_{w} / t_{f}$ is valid for the I or $\mathrm{H}$ section with constant thickness $\left(t_{f}=t_{w}\right)$.

The condition $b t_{f} /\left(h_{w} t_{w}\right)>0.6$ given in the clause 6.2.6(5) (EN 1993-1-1, 2005) is fulfilled for $t_{f}>5.44$ $\mathrm{mm}$ in Fig. 1 and for $t_{f}>3.94 \mathrm{~mm}$ in Fig. 2. For such I- and H-sections the elastic shear resistance may be calculated from the formula $V_{e l, z, R d}=A_{w} f_{y} /\left(\sqrt{3} \gamma_{M 0}\right)$, where the web area $A_{w}=h_{w} t_{w}$. The plastic shear resistance should be calculated from the formula $V_{p l, z, R d}=A_{v z} f_{y} /\left(\sqrt{3} \gamma_{M 0}\right)$, where the shear areas $A_{v z}$ are defined above.

\section{Conclusions}

The formulae (2) and (3) used in (EN 1993-1-1, 2005) may give especially for small sizes of I- or Hsections the value of the relative shear area up to 1.9. This is not acceptable, if there is no scientific background and no evidence based on experiments. The formula (1) should be changed. Such big plastic shear resistance influences in negative way also all interaction formulae, where $V_{p l, z, R d}$ is used. See the clauses 6.2.7, 6.2.8, 6.2.10 in (EN 1993-1-1, 2005). The first author proposed to use the formulae (9) for (prEN 1999-1-1, 2017). The relevant formulae are in Annex J.

\section{Acknowledgement}

Project No. 1/0603/17 was supported by the Slovak Grant Agency VEGA.

\section{References}

Beg, D., Kuhlmann, U., Davaine, L., Braun, B. (2010) Design of Plated Structures. Eurocode 3: Design of Steel Structures. Part 1-5: Design of Plated Structures. ECCS Eurocode Design Manuals. ECCS CECM EKS. Ernst \& Sohn. A Wiley Company. Berlin.

Cowper, G. R. (1966) The Shear Coefficient in Timoshenko’s Beam Theory. J. Appl. Mech. 33(2), 335-340.

DIN 18800-1 (2008) Steel structures - Part 1: Design and construction. Deutsches Institut für Normung e.V., Berlin.

EN 1993-1-1 (2005) and Corrigendum AC (2006). Eurocode 3 - Design of steel structures, Part 1-1: General rules and rules for buildings. CEN Brussels.

EN 1999-1-1 (2007) and Amendment A1 (2009) and Amendment A2 (2013). Eurocode 9 - Design of aluminium structures. Part 1-1: General structural rules.

Gruttmann, F., Wagner W. (2001) Shear correction factors in Timoshenko's beam theory for arbitrary shaped crosssections. Computational Mechanics 27, p. 199-207.

Marti, T. (2013) Theory of Structures. Fundamentals. Framed Structures. Plates and Shells, Ernst \& Sohn. Berlin. prEN 1993-1-1 (2017) Eurocode 3 - Design of steel structures, Part 1-1: General rules and rules for buildings. CEN/TC 250/SC 3/WG 1, N 229. Final Draft prepared by the Project Team SC3.T1. Date of document: 201712-18. Document stage: CEN Enquiry. CEN Brussels.

prEN 1999-1-1 (2017) Eurocode 9 - Design of aluminium structures. Part 1-1: General structural rules. CEN/TC 250/SC 9, N 579. prEN 1999-1-1 Final Draft marked. Date of document: 2017-11-02. CEN Brussels.

Timoshenko, S. P. (1940): Strength of Materials. Part 1 and 2. 2nd edn, D. Van Nostrand Company, Inc., New York. Timoshenko S. P., Goodier J. N. (1970): Theory of Elasticity, 3rd edn, McGraw-Hill.

Timoshenko, S. P., Gere, J. M. (1972) Mechanic of Materials. Van Nostrand Company, Inc., New York. Mir. Moscow (Russian translation 1976). 